\title{
Biological Characterization and Sequence Analysis of Cucumber mosaic virus isolated from Capsicum annuum
}

\author{
Minjea Kim', Seung Kook Choi ${ }^{2}$, Ju Yeon Yoon', Jang Kyung Choi ${ }^{3}$ and Ki Hyun Ryu ${ }^{1 *}$ \\ 'Plant Virus GenBank, Division of Environmental \& Life Sciences, Seoul Women's University, Seoul 139-774, Korea \\ ${ }^{2}$ USDA-ARS, Department of Plant Pathology, Cornell University, Ithaca 14853, U.S.A. \\ ${ }^{3}$ Division of Biological Environment, Kangwon National University, Chunchon 200-701, Korea \\ (Received on February 18, 2005; Accepted on March 12, 2005)
}

\begin{abstract}
Whereas most of isolates of Cucumber mosaic virus (CMV) can induce green mosaic systemic symptoms on zucchini squash, foliar symptoms of a pepper isolate of CMV (Pf-CMV)-infected zucchini squash revealed systemic chlorotic spots. To assess this biological property, infectious full-length cDNA clones of Pf-CMV were constructed using long-template RT-PCR. The complete nucleotide sequences of RNA2 and RNA3 of Pf-CMV were determined from the infectious fulllength cDNA clones, respectively. RNA 2 and RNA3 of Pf-CMV contain 3,070 nucleotides and 2,213 nucleotides, respectively. Overall sequence homology of two RNAs revealed high similarity $(90 \%)$ between CMV strains, and $60 \%$ similarity to those of Tomato aspermy virus and Peanut stunt virus strains. By sequence analysis with known representative strains of $\mathrm{CMV}$, PfCMV belongs to a typical member of CMV subgroup IA. The virus has high evolutionary relationship with Fny-CMV, but the pathology of Pf-CMV in zucchini squash was quite different from that of Fny-CMV. The pesudorecombinant virus, F1P2P3, induced chlorotic spot leaf symptom and timing of systemic symptom in squash plants, similar to the plants infected by Pf-CMV. No systemic symptoms were observed when Pf-CMVinoculated cotyledons were removed at 5 days postinoculation (dpi) while Fny-CMV showed systemic symptom at $2 \mathrm{dpi}$. These results suggest that the pepper isolate of $\mathrm{CMV}$ possesses unique pathological properties distinguishable to other isolates of CMVs in zucchini squash.
\end{abstract}

Keywords : Cucumber mosaic virus, Cucumovirus, evolution, pepper, sequence analysis, symptom, virus movement

Capsicum annuum is a vegetable giving rise to a very large phenotypic diversity depending on the country where it is cultivated and its intended use, such as fresh or cooked vegetable, ornamental, spice, or extraction of either its

\footnotetext{
*Corresponding author.

Phone) +82-2-970-5618, FAX) $+82-2-970-5610$

E-mail) ryu@swu.ac.kr
}

natural colorant for food dyes or capsaicin for use in medicine.

Over twenty-four viruses infecting peppers have been reported to cause economical problems in pepper production (Brunt et al., 1996). In pepper-infecting plant viruses, Cucumber mosaic virus (CMV) has been detrimental to pepper production in Korea, because of the widest hostrange (infecting over 1000 plants species), aphid-transmissible and the ability of synergistic effects with unrelated plant viruses (Palukaitis et al., 1992; Palukaitis and GarciaArenal, 2003). CMV, a type species of the genus Cucumovirus in Bromoviridae family, is a tripartite, positive sense RNA virus consisted of three genomic RNAs. RNA 1 encodes 1 a protein that contains domains of methyltransferase and helicase for virus replication. RNA2 encodes 2 a protein, the viral polymerase (Hayes and Buck, 1990 ) and $2 b$ protein that is essential for virus movement and infectivity in some hosts (Ding et al., 1995). Dicistronic RNA 3 encodes the 3 a protein (or movement protein: MP) for local virus movement and the capsid protein $(\mathrm{CP})$ for encapsidation. CMV RNA3 is related with symptom expression in tobacco plant and pathogenicity in squash and corn plant (Gal-On et al., 1994; Ryu et al., 1998).

To control CMV disease in pepper, various studies have been extensively demonstrated by constructions of transgenic pepper plants expressing $\mathrm{CP}$, or expressing $\mathrm{PR}$ proteins (Shin et al, 2002a, 2002b). However, it is difficult to obtain transgenic peppers conferring CMV-resistance, mostly due to poor regeneration of the plant. Although a few full-length cDNA clones of CMV have been constructed (Boccard and Baulcombe, 1993; Ding et al., 1994; Rizzo and Palukaitis, 1990; Roossinck et al., 1999; Salanki et al., 1994), the infectious clones of CMV isolated from pepper plant are not available. Here, we characterized the biological properties of a pepper strain of CMV and discussed.

\section{Materials and Methods}

Virus sources, virus propagation, purification and inoculation. Pf strain of CMV, a pepper isolate, was 
propagated in Nicotiana tabacum $\mathrm{cv}$. Xanthi-nc through mechanical inoculation after serial propagations in Chenopodium quinoa. Detection of the virus in tobacco tissue was checked by RT-PCR using Cucumovirus-genus specific primers (Choi et al., 1999) and by leaf-press immunoassay using antiserum against CMV subgroup I. Fny-CMV and Sny-CMV were used as control in this study (Ryu et al., 1998). The tobacco leaves collected 10 days after inoculation were used for virus purification, as previously described by Peden and Symons (1979). The cotyledons of zucchini squash (Cucurbita pepo cv. Black Beauty) were inoculated by saps from infected tobacco plants or in vitro transcripts of pseudorecombinants as described below. Inoculated plants were grown in controlled greenhouse conditions with the temperature at $26^{\circ} \mathrm{C}$ (daytime) or $20^{\circ} \mathrm{C}$ (night).

Construction of infectious clones and sequence analysis of RNAs. To construct full-length cDNAs of Pf RNA2 and RNA3, the viral RNA was extracted from the purified virions by sodium dodecyl sulfate (SDS)-phenol extraction method (Choi et al., 1999; Gal-On et al., 1994). The purified viral RNAs were used as a template for RT-PCR. Briefly, RT-PCR was carried out at $42^{\circ} \mathrm{C}$ for $60 \mathrm{~min}$ with a reverse primer (5'-AATTCTGCAGTGGTCTCCTTTTRGAGGCC-3') containing PstI site (under lined) and each specific forward primer containing BamHI site and $\mathrm{T} 7$ RNA promoter, as described by Choi et al. (2003). The purified cDNAs of Pf RNAs were ligated into pUC18 digested with the same restriction enzymes to generate construct PPF-CMV2 and pPF-CMV3, respectively. To determine RNA 2 and RNA3 sequences, two clones (pPFCMV2 and PPF-CMV3) were digested by using Pst I-Sall, Sal I-BamHI and KpnI-BamHI. The digested DNA fragments corresponding to RNA2 or RNA3 were cloned into pSK(-) vector digested by each combinational restriction enzymes, respectively. Transformation of E. coli and gene manipulation were performed by standard protocols (Sambrook et al., 1989). Nucleotide sequences of Pf-RNA2 and Pf-RNA3 were determined by dye-termination methods (Sanger et al., 1977) on both directions. The determined sequences were analyzed by using the alignments of corresponding sequences from Cucumovirus-representative strains through MagAlign CLUSTAL $\mathrm{V}$ in DNASTAR package program (Madison, US).

Infectivity assay of reassortment on host plant. Both pPF-CMV2 and pPF-CMV3 were linearized by $P_{s t} \mathrm{I}$ digestion followed by Klenow fragment for blunt-end for in vitro transcription reaction. Full-length capped transcripts corresponding to RNA 2 and RNA3 of Pf-CMV were obtained by in vitro transcription system with T7 RNA polymerase (Promega Corp.) in the presence of cap analogue $\mathrm{m}^{7} \mathrm{GpppG}$ (New England Biolabs, U.K.) as described by Choi et al. (2003). Young tobacco plants were inoculated with a mixture of Pf-RNA2 and Pf-RNA3 mixed with capped transcripts of Fny-RNA1, prior to inoculation of zucchini squash (Cucurbita pepo cv. Black Beauty) (Choi et al., 2004).

Extraction and analysis of CMV RNAs. Northern blot hybridisation analysis was done to detect CMV RNA accumulation in leaves of zucchini squash. About $200 \mathrm{mg}$ of leave tissue or $1 \mathrm{ml}$ of the protoplast solution $\left(0.5 \times 10^{6}\right.$ cells $/ \mathrm{mL}$ ) was extracted with $400 \mathrm{~mL}$ of $50 \mathrm{mM}$ Tris- $\mathrm{HCl}$ (pH 8.0) containing $10 \mathrm{mM}$ EDTA and $2 \%$ SDS. The samples were then extracted with phenol, and the RNAs were precipitated using standard protocols (Sambrook et al., 1989). Total RNAs were fractioned by electrophoresis on $1.6 \%$ agarose-formaldehyde denaturing gel and were transferred to positively charged nylon membranes (Roche Diagnostics) by the capillary method. The membrane was cross-linked by UV and hybridised to digoxigeninlabeled RNA probes complementary to the 3 ' noncoding region of all Fny-CMV RNAs (Gal-On et al., 1994). The labelled RNA probes were detected using the DIG Luminescent Detection kit with CSPD (Roche Diagnostics). All experiments described here were performed at least three times.

\section{Results and Discussion}

Biological properties and virus movement kinetics of Pf-CMV. Pf-CMV induced typical mosaic symptom on tobacco on its uninfected systemic leaves indistinguishable to Fny-CMV. Whereas most of known isolates of CMVs can induce green mosaic systemic symptoms on zucchini squash, symptoms of Pf-CMV-infected zucchini squash revealed chlorotic spots (Fig. 1). Unlike either M-CMV or Fny-CMV, Pf-CMV was not restricted from systemic infection of zucchini squash, but apparently was delayed in symptom development, systemic movement or both. Therefore, to gain further insight into the various interactions between viruses and hosts leading to a delay in symptom development, it was of interest to characterise the nature and genetic basis of the differences in pathogenicity associated with Pf-CMV. This was done by comparison to the better-characterized and faster moving Fny-CMV used in similar previous studies. Pathology of Pf-CMV developed much milder symptoms in zucchini squash, starting at 9dpi. Unlike M strain of CMV (Ryu et al., 1998), Pf-CMV was not restricted from systemic infection of zucchini squash, and systemic symptom expression was delayed in squash plants (Fig. 1). Leaf-press immunoassay revealaed 
A

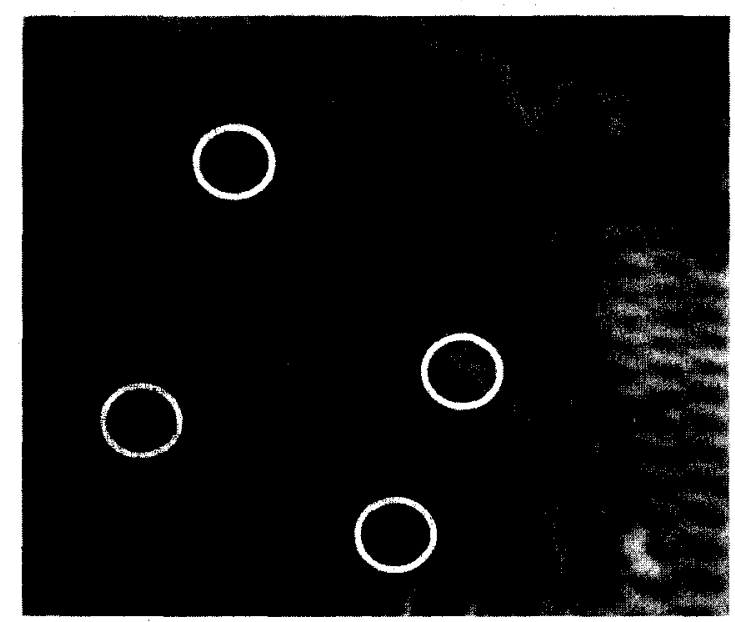

B

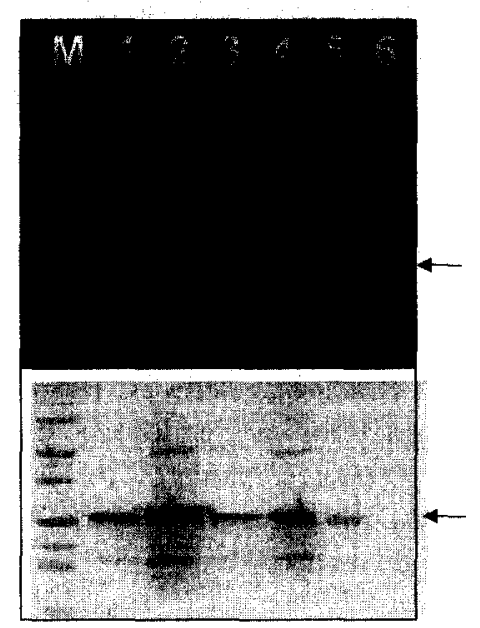

Fig. 1. Systemic chlorotic spots leaf symptoms of Pf-CMV in zucchini squash (A), and detection of the virus (B) from inoculated cotyledon (B lane 2) and uninfected upper leaf (B lanes 3-5) as determined by RT-PCR and western blot. Lane 1: Fny-CMV positive control; lane 2: Pf-CMV-inoculated cotyledon; lane 3: upper leaf of Pf-CMV-infected plant; lane 4: chlorotic lesion of upper leaf of PfCMV-infected plant; lane 5: normal part of upper leaf of Pf-CMV-infected plant; lane 6: healthy control.

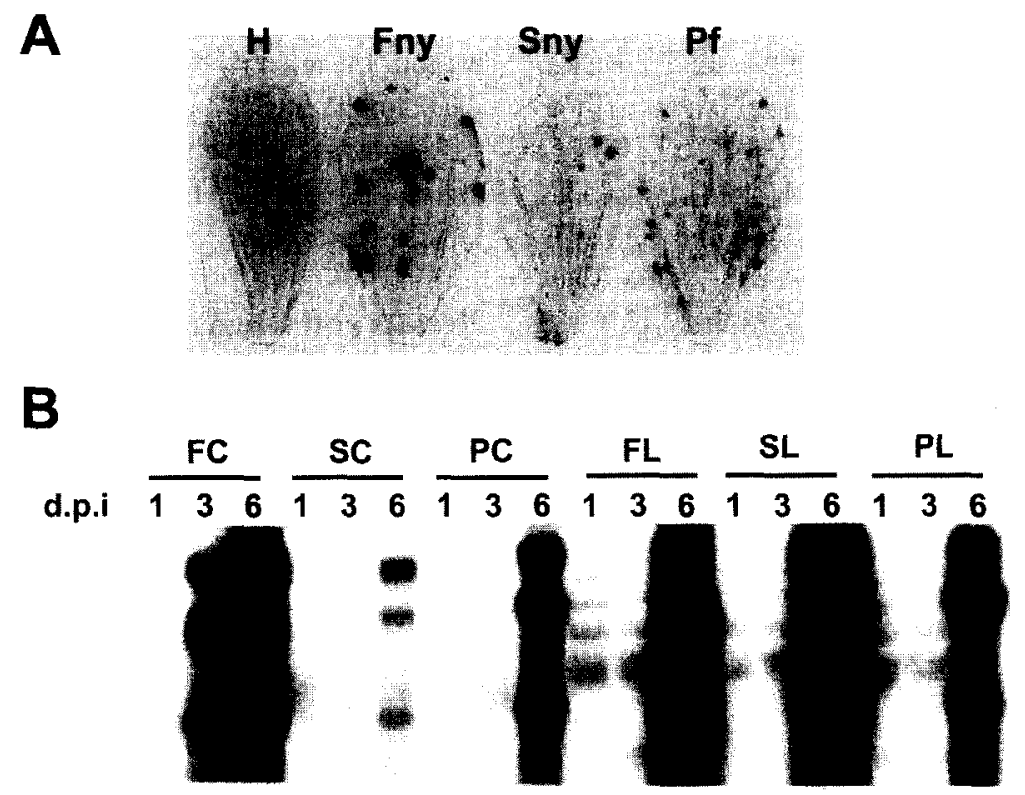

Fig. 2. Leaf-press immunoassay of cell-to-cell movement of three strains of CMV in zucchini squash cotyledons (A). H: healthy; Fny: Fny-CMV; Sny: Sny-CMV; Pf: Pf-CMV. Purple color foci show the presence of CMV (A). Analysis of CMV RNA accumulation in inoculated cotyledons (FC, SC and PC) and uninfected upper leaves (FL, SL and PL) detected by Northern blot hybridization (B). FC: Fny-CMV-inoculated cotyledon; SC: Sny-CMV-inoculated cotyledon; PC: Pf-CMV-inoculated cotyledon; FL: upper leaves of FnyCMV-infected part; SL: upper leaves of Sny-CMV-infected part; PL: upper leaves of Pf-CMV-infected part.

that Pf-CMV moved moderately while Fny-CMV moved faster and Sny-CMV moved slowely (Fig. 2). This was due to delay of replication in inoculated cotyledon of Pf-CMV (Fig. 2). No systemic symptoms were observed when PfCMV-inoculated cotyledons were removed at 5 days postinoculation (dpi) while Fny-CMV showed systemic symptom at 2 dpi (data not shown).
Comparative sequence analyses of RNA2 and RNA3 of Pf-CMV. The nucleotide (nt) sequences were determined from the full-length cDNA clones of RNA 2 and RNA3 of Pf-CMV. The determined nucleotide sequences and deduced amino acid sequences of Pf-CMV RNA 2 and RNA 3 were compared to several representative strains of CMV and two other species in the genus Cucumovirus (Table 1). 
Table 1. Percentage of amino acid identities of proteins encoded in RNA 2 and RNA3 between Pf-CMV and other members of the genus Cucumovirus ${ }^{\mathrm{a}}$

\begin{tabular}{lccccc}
\hline \hline \multirow{2}{*}{ Virus } & \multicolumn{2}{c}{ RNA2 } & & \multicolumn{2}{c}{ RNA3 } \\
\cline { 2 - 3 } \cline { 5 - 6 } & $2 \mathrm{a}$ & $2 \mathrm{~b}$ & & MP & CP \\
\hline Fny-CMV & 98.4 & 98.2 & & 99.3 & 99.1 \\
Mf-CMV & 97.0 & 94.5 & & 98.6 & 98.6 \\
Y-CMV & 98.5 & 94.8 & & 98.6 & 95.4 \\
As-CMV & 93.5 & 81.8 & & 92.8 & 96.3 \\
K-CMV & 94.5 & 82.7 & & 94.3 & 97.7 \\
LS-CMV & 75.0 & 48.0 & & 82.4 & 78.9 \\
Q-CMV & 73.1 & 48.0 & & 81.4 & 70.6 \\
KC-TAV & 56.3 & 28.4 & & 64.9 & 43.1 \\
V-TAV & 56.3 & 28.4 & & 64.2 & 43.1 \\
ER-PSV & 51.9 & 34.4 & & 64.2 & 44.5 \\
\hline
\end{tabular}

${ }^{a}$ GenBank accession numbers for sequences are as follows: Pf-CMV (in this study, AB096214, AJ237850), Fny-CMV (D00355, D10538), Mf-CMV (AJ 276480, AJ276481), Y-CMV(D12538, D83958), As-CMV (AF033667, AF013291), K-CMV (S72187, AF127977), LS-CMV (AF416900, AF127976), Q-CMV (X00985, J02059), KC-TAV (AJ320274, AJ323849), V-TAV (D10663, L79972) and ER-PSV (NC_002039, U15730).

The nucleotide sequences of RNA2 and RNA3 reported in this work have been assigned accession number AB096214 and AJ237850, respectively. The cDNA corresponding for RNA2 of Pf-CMV is 3050 bp long. The sequence similarity of RNA2 of Pf-CMV is approximately $90 \%$, compared to the corresponding protein of cucumoviruses (Table 1). The predicted 2 a protein (RNA dependent RNA polymerase, 97 $\mathrm{kDa}$ ) is translated from $87 \mathrm{nt}$, ATG start codon, and terminated at position of $2660 \mathrm{nt}$. Four consensus RNA polymerase domains are found at nt 759 to $n t 2358$ in central part of 2 a protein, while there are a little variations in the C-terminal region (Szilassy et al., 1999). The internal control region of tRNA promoters-like sequence, 5'GCGUACGGUUCAACCCU-3', is located at 3 ' end of RNA2. In this region, RNA2 of Pf-CMV, would be formed a hairpin structure that interacted with complementary sequences of CMV-satellite RNA, like other strains of CMV (Moriones et al., 1991; Rezaian et al., 1985).

The $2 \mathrm{~b}$ protein, another overlapping protein is expressed at the position of nt 2419 to $\mathrm{nt} 2751$ by subgenomic transcription, resulting in RNA 4A (Ding et al., 1994; 1995). Although the subgenomic RNA4A of Pf-CMV was not detected in RNAs from purified virus particles or in total RNAs from infected tobacco plant (data not shown). The sequence similarity of $2 \mathrm{~b}$ protein in same subgroups of CMV is approximately $95 \%$, but the $2 \mathrm{~b}$ protein homology is quite distinguished between CMV and TAV or between CMV and PSV (Table 1). It is known that protein sequence of $2 b$ is more highly divergent among overall expressed viral proteins in the genus Cucumovirus. The nucleustargeting signal of $2 \mathrm{~b}$ protein is important for RNA silencing function (Lucy et al., 2000) and the $2 \mathrm{~b}$ protein is required for pathogenicity on host plants (Ding et al., 1995). Thus, it highly likely that heterogeneity of $2 \mathrm{~b}$ gene gives virus adaptation to various host plants.

The RNA3 of Pf-CMV, 2213 nucleotides in length is dicistronic and encodes $3 \mathrm{a}$ movement protein and $\mathrm{CP}$ separated by $298-n t$ long intercistronic region contained ICR-2-like conserved motif that is necessary for synthesis of subgenomic RNA like CMV and Brome mosaic virus (Boccard and Baulcombe, 1993, Smirnyagina, et al., 1994). High values for percentage of nucleotide sequence identities were revealed between TAV and PSV or between CMV and TAV (data not shown). The 3a movement protein of PfCMV compared to the corresponding protein of $\mathrm{CMV}$ strains and cucumovirus strains had approximate $99.3 \%$ to $64.2 \%$ sequence homology. The percentage nucleotide sequence identity in the $\mathrm{CP}$ gene between $\mathrm{CMV}$ strains and other strains of cucumoviruses were revealed to be sequence similarity that ranges from $99 \%$ to $43 \%$. The phylogenetic tree of $\mathrm{CP}$ indicates Pf-CMV is closer to Fny-CMV and Mf-CMV (Fig. 3). This result indicates that Pf-CMV belongs to subgroup IA (Roossinck et al., 1999). Although $\mathrm{CP}$ homology between Pf and Fny strain is the highest value among viruses analyzed in this study (Table 1), the pathogenicity of two strains on squash plants was quite different. The CP homology result demonstrates The CP analysis of Pf-CMV indicates that the closer evolutionary relationship of CMV to PSV than that of CMV to TAV, and such similar relationships were also shown on comparison of overall cucumovirus RNA3 (Table 1 and Owen et al., 1990).

In addition, 5' non-coding region (NCR) of Pf RNA3 contains the conserved UG-tract, like those of other cucumoviruses known to be cis-acting element for the accumulation of CMV RNA3 (Boccard and Baulcombe, 1993). The 3' NCR of Pf RNA3 contains the highly conserved 40-nt sequence (5'-GAACGGGUGUCCAUCCAGCUUACGGCUAAAAUGGUCAGU-3': from 2012 $\mathrm{nt}$ to $2051 \mathrm{nt}$ in Pf RNA3) found in all cucumoviruses sequenced (McGarvey et al., 1995).

Infectivity test of infectious cDNA clones of Pf-CMV. PfCMV developed much milder symptoms in zucchini squash, starting at 9 dpi. To know which Pf-RNA(s) is (are) involved in this distinguished pathology, pseudorecombination test was done by comparison to the better characterised and faster moving Fny-CMV used in similar previous studies (Gal-On et al., 1994; Roossinck and Palukaitis, 1990; Wong et al., 1999). Capped RNA transcripts were synthesized by $\mathrm{T} 7$ transcription in vitro from 


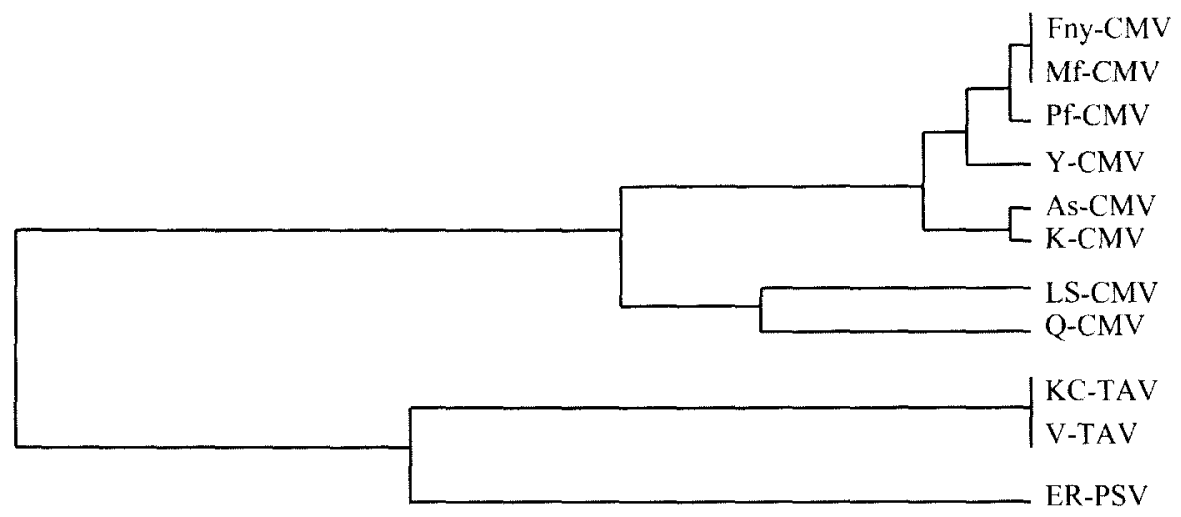

0.05

Fig. 3. Phylogentic tree analysis of Pf-CMV and representative strains of CMV and species of the genus Cucumovirus based on amino acid sequences of coat protein gene.

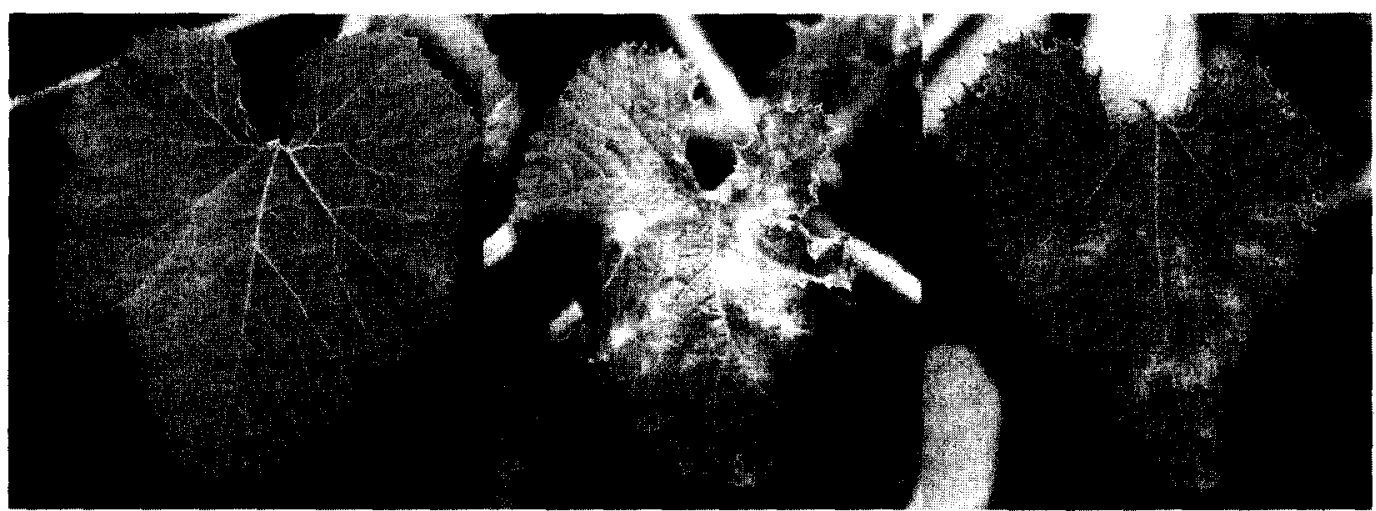

Mock

Pf-CMV

F1P2P3

Fig. 4. Infectivity assay and symptom expression of in vitro RNA transcripts from full-length cDNA clone of RNA2 and RNA3 of PfCMV in zucchini squash cv. Black Beauty. The synthesized transcripts RNA2 and RNA3 were mixed equally with transcripts of FnyRNAI, resulting in the pseudorecombinant F1P2P3.

pFny109, pPF-CMV2, and pPF-CMV3. The pseudorecombinant transcript mixture containing each RNAs required for infection, designated as F1P2P3, was inoculated to Nicotiana tabacum (cv. Xanthi-nc), prior to inoculation of squash plants. The tobacco plants infected by F1P2P3 show the typical mosaic symptom similar to that of Pf-CMV about 12-14 days post-inoculation (data not shown). Subsequently, the zucchini squash plants infected by F1P2P3 are expressed systemically chlorotic spot similar to Pf-CMV (Fig. 4). This result suggests that the determinants of Pf-CMV involved in symptom expression and virus movement are located on RNA2 and RNA3.

Although more experiments are necessary to determine viral proteins responsible for the delay of symptom and virus movement or host factors interacted with viral proteins, several studies with CMV and other viruses have implicated the polymerase protein as being involved in virus movement (Chen et al., 1996; Deom et al., 1997; Nelson and van Bel, 1998). It is shown that two changes in the polymerase protein affected the elicitation of a hypersensitive response and restriction of CMV to the local lesion in cowpea (Kim and Palukaitis, 1997). In addition, both RNAs 2 and 3 is involved in host-specific infection in radish (Takeshita et al., 1998). There are many studies of MP and CP involved in symptom production, according to complicated effect of cell-to-cell movement and systemic movement in host plants (Canto and Palukaitis, 1998; Canto et al., 1997; Kaplan et al., 1997). Therefore, to gain further insight into the various interactions between viruses and hosts resulting in delay of symptom development, it is interesting to characterize the differences in pathogenicity associated with Pf-CMV. 


\section{Acknowledgements}

This study was supported by grants of BioGreen 21 program from the Rural Development Administration, in part by the grants of Strategic R \& D program (LMO Biosafety) from the KISTEP in Korea, and in part by grants from the Agricultural Research \& Promotion Center from the Ministry of Agriculture and Fishery in Korea.

\section{References}

Boccard, F. and Baulcombe, D. 1993. Mutational analysis of cisacting sequence and gene function in RNA3 of cucumber mosaic virus. Virology 193:563-578.

Brunt, A., Crabtree, K., Dallwitz, M., Gibbs, A. and Watson, L. 1996. Viruses of Plants: Descriptions and Lists from the VIDE Database. 1484 pp. C.A.B. International, U.K.

Canto, T., Prior, D. A., Hellwald, K. H., Oparka, K. J. and Palukaitis, P. 1997. Characterization of cucumber mosaic virus. IV. Movement protein and coat protein are both essential for cellto-cell movement of cucumber mosaic virus. Virology 237:237-248.

Canto, T. and Palukaitis, P. 1998. Transgenically expressed cucumber mosaic virus RNA1 simultaneously components replication of cucumber mosaic virus RNA 2 and 3 and confers resistance to systemic infection. Virology 250:325-336.

Chen, J., Watanabe, Y., Sako, N., Ohshima, K. and Okada, Y. 1996. Mapping of host range restriction of the Rakkyo strain of tobacco mosaic virus in Nicotiana tabacum cv. Bright Yellow. Virology 226:198-204.

Choi, S. K., Ahn, H. I., Kim, M. J., Choi, J. K. and Ryu, K. H. 2004. Symptom determinant as RNA3 of lily isolates of Cucumber mosaic virus on zucchini squash. Plant Pathol. J. 20:212-219.

Choi, S. K., Choi, J. K., Park, W. M. and Ryu, K. H. 1999. RTPCR detection and identification of three species of cucumoviruses with a genus-specific single pair of primers. J. Virol. Methods 83:67-73.

Choi, S. K., Choi, J. K. and Ryu, K. H. 2003. Involvement of RNA2 for systemic infection of Cucumber mosaic virus isolated from lily on zucchini squash. Virus Res. 97:1-6.

Deom, C. M., Quan, S. and He, X. Z. 1997. Replicase proteins as determinants of phloem-dependent long-distance movement of tobamovinuses in tobacco. Protoplasma 19:1-8.

Ding, S. W., Anderson, B. J., Haase, H. R. and Symons, R. H. 1994. New overlapping gene encoded by the cucumber mosaic virus genome. Virology 198:593-601.

Ding, S. W., Li, W. X. and Symons, R. H. 1995. A Noble naturally occuring hybrid gene encoded by a plant RNA virus facilitates long distance virus movement. EMBO J. 14:5762-5772.

Gal-On, A., Kaplan, I. B., Roossinck, M. J. and Palukaitis, P. 1994. The kinetics of infection of zucchini squash by cucumber mosaic virus indicate a function for RNA 1 in virus movement. Virology 187:499-507.

Hayes, R. J. and Buck, K. W. 1990. Complete replication of a eukaryotic virus RNA in vitro by a purified RNA-dependent RNA polymerase. Cell 63:363-368.

Kaplan, I. B., Gal-On, A. and Palukaitis, P. 1997. Characterization of cucumber mosaic virus. III. Localization of sequence in the movement protein controlling systemic infection in cucurbits. Virology 230:343-349.

Kim, C. H. and Palukaitis, P. 1997. The plant defense response to cucumber mosaic virus in cowpea is elicited by viral polymerase gene and affects virus accumulation in single cells. EMBO J. 16:4060-4068.

Lucy, L. P., Guo, H. H., Li, X. W. and Ding, S. W. 2000. Suppression of post-transcriptional gene silencing by a plant viral protein localized in the nucleus. EMBO J. 9:1672-1680.

McGarvey, P., Tousignant, M., Geletka, L., Cellini, F. and Kaper, J. M. 1995. The complete sequence of a cucumber mosaic virus from Ixora that is deficient in the replication of satellite RNAs. J. Gen. Virol. 76:2257-2270..

Moriones, E., Roossinck, M. J. and Garcia-Arenal, F. 1991. Nucleotide sequence of tomato aspermy virus RNA 2. J. Gen. Virol. 72:779-783.

Nelson, R. S. and van Bel, A. J. E. 1998. The mystery of virus trafficking into, through and out of vascular tissue. Prog. Bot. 59:476-533.

Palukaitis, P., Roossinck, M. J., Dietzgen, R. G. and Francki, R. I. B. 1992. Cucumber mosaic virus. Adv. Virus Res. 41:281-348.

Palukaitis, P. and Garcia-Arenal, F. 2003. Cucumoviruses. $A d v$. Virus Res. 62:241-323.

Peden, K. W. C. and Symons, R. H. 1979. Cucumber mosaic virus contains a functionally divided genome. Virology 53:487-492.

Rezaian, M. A., Williams, R. H. V. and Symons, R. H. 1985. Nucleotide sequence of cucumber mosaic virus RNA1. Presence of a sequence complementary to part of the viral satellite RNA and homologies with other viral RNAs. Eur. J. Biochem. 150:331-339.

Rizzo, T. M. and Palukaitis, P. 1990. Construction of full-length cDNA clones of cucumber mosaic virus RNAs 1, 2, and 3: generation of infectious RNA transcripts. Mol. Gen. Genet. 222:249-256.

Roossinck, M. J. and Palukaitis, P. 1990. Rapid induction and severity of symptoms in zucchini squash (Cucurbita pepo) map to RNA 1 of cucumber mosaic virus. Mol. Plant-Microbe Interact. 3:188-192.

Roossinck, M. J., Zhang, L. and Hellwald, K. H. 1999. Rearrangements in the $5^{\prime}$ nontranslated region and phylogenetic analyses of cucumber mosaic virus RNA 3 indicate radial evolution of three subgroups. J. Virol. 73:6752-6758.

Ryu, K. H., Kim, C. H. and Palukaitis, P. 1998. The coat protein of cucumber mosaic virus is a host range determinant for infection of maize. Mol. Plant-Microbe Interact. 11:351-357.

Salanki, K., Balazs, E. and Burguan, J. 1994. Nucloetide sequence and infectious in vivo transcripts of RNA3 of tomato aspermy virus pepper isolate. Virus Res. 33:281-289.

Sambrook, J., Fritsch, E. F. and Maniatis, T. 1989. Molecular Cloning: A Laboratory Manual, $2^{\text {nd }}$ ed. Cold Spring Harbor Laboratory Press, New York.

Sanger, F., Nicklen, S. and Coulson, A. R. 1977. DNA sequencing 
with chain-terminating inhibitors. Proc. Natl. Acad. Sci. USA 74:5463-5467.

Shin, R., Han, J. H., Lee, G. J. and Paek, K. H. 2002a. The potential use of a viral coat protein gene as a transgene screening marker and multiple virus resistance of pepper plants coexpressing coat proteins of cucumber mosaic virus and tomato mosaic virus. Transgenic Res. 11:215-219.

Shin, R, Park, J. M., Ah, J. M. and Paek, K. H. 2002b. Ectopic expression of Tsil in transgenic hot pepper plants enhances host resistance to viral, bacterial, and oomycete pathogens. Mol. Plant Microbe Interact. 15:983-989

Smirnyagina, E., Hsu, Y. H., Chua, N. and Ahlquist, P. 1994. Second-site mutations in the brome mosaic virus RNA3 intercis- tronic region partially suppress a defect in coat protein mRNA transcription. Virology 198:427-436.

Szilassy, D., Salanki, K. and Balzas, E. 1999. Molecular evidence for the existence of two distinct subgroups in cucumber mosaic virus Virus Genes 18:221-227.

Takeshita, M., Suzuki, M., Kuwata, S. and Takanami, Y. 1998. Involvement of cucumber mosaic cucumovirus RNA 2 and RNA 3 in viral systemic spread in radish plant. Arch. Virol. 143:1109-1117.

Wong, S. M., Thio, S. S. C., Shinkaku, M. H. and Palukaitis, P. 1999. The rate of cell-to-cell movement in squash of cucumber mosaic virus is affected by sequences of the capsid protein. Mol. Plant-Microbe Interact. 12:628-632. 